\title{
Obstetric and perinatal outcomes of expectant management and immediate induction of labour in term premature rupture of
} membranes: promising outcomes from expectant management cohort

\author{
Sunil E. Tambvekar ${ }^{1 *}$, Shobha N. Gudi ${ }^{2}$ \\ ${ }^{1}$ Department of Obstetrics and Gynecology, Nowrosjee Wadia Maternity Hospital, Mumbai, Maharashtra, India \\ ${ }^{2}$ Department of Obstetrics and Gynecology, St. Philomena's Hospital, Bangalore, Karnataka, India
}

Received: 28 December 2021

Revised: 09 January 2022

Accepted: 10 January 2022

\section{*Correspondence:}

Dr. Sunil E. Tambvekar,

E-mail: s.tambvekar@hotmail.com

Copyright: () the author(s), publisher and licensee Medip Academy. This is an open-access article distributed under the terms of the Creative Commons Attribution Non-Commercial License, which permits unrestricted non-commercial use, distribution, and reproduction in any medium, provided the original work is properly cited.

\begin{abstract}
Background: Premature rupture of membranes (PROM) is common obstetric entity, the management even at term is controversial and there is no consensus for definite protocol of management. Objective of the present study is to compare the effectiveness, safety of expectant management of 24 hours and immediate induction with $\mathrm{PGE}_{2}$ gel in terms of maternal and fetal outcome in term PROM.

Methods: 200 women were randomized to group A expectant management and group B immediate induction, after strict Inclusion and exclusion criteria. In expectant group waiting period was 24 hours. Multiple end points were examined throughout management. Chi square test and independent $\mathrm{t}$ tests were performed for statistical analysis. $\mathrm{P}$ value $<0.05$ was considered significant.

Results: Demographic parameters of patients, maternal and gestational age were similar in both groups. Primigravidae were more in both groups A and B. Vaginal delivery rate is more in expectant group and Caesarean Section rate is high in immediate induction group. CS rate was $37 \%$ and $23 \%$ in group A and B respectively; the difference is statistically significant ( $\mathrm{p}$ value $=0.031)$. 'ROM to delivery interval' was more in group A $(16.31 \pm 8.67 \mathrm{hrs}$ and $13.85 \pm 5.46 \mathrm{hrs})(\mathrm{p}$ value $=0.0256)$. Hospital stay was comparatively more in group A $(5.40 \pm 0.81$ days and $4.11 \pm 0.86$ days $)(p$ value $=0.435)$. Infective morbidity of mother and baby was low in both groups and no difference was seen.

Conclusions: An expectant management allows a good number of women to go into labour and deliver vaginally without an increase in CS rate and infectious morbidity for mother and fetus.
\end{abstract}

Keywords: Term PROM, Expectant management, Immediate induction, $\mathrm{PGE}_{2}$ gel, Caesarean section rate

\section{INTRODUCTION}

'Premature rupture of membranes' (PROM) refers to the loss of integrity of membranes before onset of labor, with resulting leakage of amniotic fluid and establishment of communication between the amniotic cavity and the endocervical canal and vagina. ${ }^{1}$

PROM occurs in approximately 5-10\% of all pregnancies, of which approximately $80 \%$ occur at term (term PROM). ${ }^{2}$ Causes like infection, trauma, APH, hydromnios, multiple gestation and coitus in pregnancy contribute to PROM. However, it is often not possible to pin point the exact cause in an individual case. Interestingly, at term, PROM can be a physiological variation rather than a pathological event. $^{3}$

Approximately $60-70 \%$ of term PROM cases are followed by the onset of labor within 24 hours and an additional 20$30 \%$ start within 72 hours. ${ }^{1,4}$ PROM is associated with increased risk of chorioamnionitis, unfavourable cervix and dysfunctional labour, increased caesarean rates, 
postpartum haemorrhage and endometritis in the mother. In the fetus, depending on gestation there is increased occurrence of hyaline membrane disease, intraventricular haemorrhage, sepsis, cord prolapse, fetal distress, increased fetal wastage.

The management of a case of PROM has remained as one of the most difficult and controversial problems in obstetrics over the past several decades.

Expectant management is implicated for various maternal and fetal complications generally for infection. Hence induction of labour could be advised, but there remains associated risk of increased caesarean section rates.

Present study was a prospective study undertaken to compare maternal and neonatal outcomes of immediate induction with intracervical $\mathrm{PGE}_{2}$ gel and expectant management (24 hours) in term PROM cases and hence to compare effectiveness and safety of both the modes of treatment.

\section{METHODS}

This was a prospective study conducted in 200 women at term gestation with PROM, admitted at conducted at department of obstetrics and gynaecology, St. Philomena's Hospital, Bangalore. Approval from Scientific committee and Ethics committee of hospital was obtained. Informed and written consent was obtained from women enrolled in the study.

Inclusion criteria set was- women diagnosed with PROM with singleton pregnancy with cephalic presentation, gestational age between 37 and 41 completed weeks, H/O of leaking PV-PROM<24 hrs, no signs and symptoms of labour, no evidence of fetal compromise, no evidence of infection-chorioamnitis. And exclusion criteria set waswomen in labour, contraindications to induction of labour (e.g. placenta previa, Prev. LSCS), contraindications to expectant management (e.g. Meconium stained liquor, APH), medical or obstetric complications indicating prompt delivery (e.g. severe pre-eclampsia, IUGR), malpresentations, multiple gestations.

Patients were enrolled in the study after accurate history taking. A thorough, general and systemic examination were performed to exclude exclusion criteria. A detailed obstetric examination was done to note presentation, uterine contractions status, and fetal heart rate pattern. Speculum examination was done to confirm leakingconfirming gush of amniotic fluid draining from cervical OS and accumulating in posterior fornix.

In doubtful cases, further tests such as $\mathrm{pH}$ estimation of discharge- Litmus paper test, fern tests were done. High vaginal swab was sent for culture and sensitivity. Vaginal examination was done to note the dilatation and effacement and to confirm the presence of membranes and to exclude the women who have set into labour.
Total number of patients with term PROM recruited in the study was 200; they were assigned group A and group B randomly. Group A consisted 100 patients assigned to expectant management (24 hours) and group B consisted 100 patients assigned to immediate induction of labour by intracervical $\mathrm{PGE}_{2}$ gel instillation. Randomization achieved by alternately recruiting the patients to individual group. They were kept under observation. Observations include PR, BP, uterine activity and FHR. Time interval from the time of administering $\mathrm{PGE}_{2}$ gel to the onset of labour was also recorded. If labour did not supervene after 8 hours or there was no improvement in Bishop score, application of $\mathrm{PGE}_{2}$ gel was repeated. Vaginal examination repeated every $6 \mathrm{hrs}$ and progress noted with Bishop score.

Women in the expectant management group were closely observed for $24 \mathrm{hrs}$. Monitoring included temperature recording every $4^{\text {th }}$ hourly, FHR hourly, digital examination was avoided until women were in active labour clinically, induction was planned if chorioamnionitis develops. If labour was not established after 24 hours reinduction with intracervical $\mathrm{PGE}_{2}$ was performed depending on cervical ripening. Injection Oxytocin was used for augmentation of labour depending on intensity of contractions, it was not used as induction agent.

Investigations performed were heamoglobin, Total WBC count, differential count, CRP, HVS culture and sensitivity, urine routine, urine culture and sensitivity were done for all the patients on admission, apart from routine ante-natal investigations. All patients irrespective of duration of PROM were given injection Ceftriaoxone $1 \mathrm{~g}$ IV $12^{\text {th }}$ hourly and injection Metronidazole $500 \mathrm{mg}$ IV $8^{\text {th }}$ hourly till delivery. The data was statistically analysed using IBM SPSS version 22. Data was analysed by using Chi-square test, paired-t test, independent $t$ test. $\mathrm{P}$ value $<0.05$ was considered as significant.

\section{RESULTS}

Basic demographic characters were similar in both the groups. The majority of patients in A and B belonged to 22-27 years of age with mean of $25.72 \pm 3.59$ and $25.48 \pm 3.4$ in $\mathrm{A}$ and $\mathrm{B}$ respectively. The mean gestational age was $38.08 \pm 0.98$ and $38.30 \pm 0.82$ weeks in group $\mathrm{A}$ and $\mathrm{B}$ respectively. $73 \%$ and $75 \%$ women in group A and B respectively were nulliparous; $27 \%$ and $25 \%$ were multiparous (parity $>1$ ) in group A and B respectively (Table 1).

The mean 'rupture of membranes' to 'admission' interval in group A and B was 5.33 \pm 3.14 hours and 4.90 \pm 5.22 hours respectively ( $\mathrm{p}=0.421$, not statistically significant). On admission the Bishop's score in women ranged mostly from 4 to $7.34 \%$ and $42 \%$ had Bishop's score less than 6 in group A and B respectively. In expectant management group high vaginal swab for culture grew E. coli in one Patient and Pseudomonas in 2 patients. In immediate 
induction group one was positive for E. coli, one for ' group B streptococci' and one showed Diptheroid insignificant growth; Insignificant growth was considered culture negative, hence total two were positive in Immediate induction group. All other patients had no growth in the high vaginal swabs.

In expectant management group 89 patients $(89 \%)$ went into spontaneous labour over given expectancy of 24 hours. Other 11 patients $(11 \%)$ required induction by $\mathrm{PGE}_{2}$ gel at 24 hours; out of them 2 patients (2\%) required 2 doses of $\mathrm{PGE}_{2}$; which were given 8 hours apart. In immediate induction group 84 patients $(84 \%)$ responded to single application of $\mathrm{PGE}_{2}$ gel and went into labour. Out of other 16 patients 11 patients $(11 \%)$ required 2 doses and 5 patients $(5 \%)$ required 3 doses of $\mathrm{PGE}_{2}$. $\mathrm{PGE}_{2}$ doses were repeated at 8-hour interval (Figure 1). 51 out of 77 patients in expectant group and 43 out of 63 patients in immediate induction group required augmentation with oxytocin. The difference was not statistically significant.

LSCS, operative delivery and spontaneous vaginal delivery rates in expectant group were $23 \%, 9 \%$ and $68 \%$ respectively. And the same in immediate induction group were $37 \%, 7 \%$ and $56 \%$ respectively. Spontaneous vaginal delivery rate is more in expectant group (Table 2); The comparison between LSCS rate and vaginal delivery as shown in Table 3 clearly states the difference with high rate of LSCS in immediate induction group. $77 \%$ women delivered vaginally in expectant group as compared to $63 \%$ in immediate induction group. LSCS rate being $23 \%$ and $37 \%$ in expectant group and immediate induction group respectively. The difference is statistically significant ( $\mathrm{p}$ value was $<0.05$ by Chi square test) (Table $3)$. The association between LSCS rate and immediate induction group calculated by Odd's ratio with $95 \% \mathrm{CI}$ was 1.97 (logistic regression); i.e.; women in immediate induction group have 1.97 times risk of undergoing LSCS.

When mode of delivery was compared between nullipara and multipara, LSCS rate was high in immediate induction group in nullipara group; $\mathrm{p}$ value here was 0.052 . The difference between the same in multipara group is not significant (Table 4). Indications for LSCS in both the groups were observed and compared. Fetal distress and failed induction were common indications in immediate induction group i.e.; $24.32 \%$. CPD and non-progress of labour were major contributory factors for LSCS in both the groups. 3 cases in expectant group underwent LSCS in view of and at the earliest evidence of developing sepsis/chorioamnitis (13.04\%). The differences when indications for LSCS are compared are not statistically significant. Table 5 shows number of vaginal examinations conducted in both groups during the course of management. More number of vaginal examinations were conducted in expectant management group i.e.; 5-8 examinations in $26 \%$ and $\geq 9$ examinations in $4 \%$ women. The same in immediate induction group were less i.e., $19 \%$ and $0 \%$ respectively. This difference is statistically significant, $\mathrm{p}$ value being 0.048 . More number of vaginal examinations were performed in expectant management group.

Mean duration of active labour in group A and B was $7.31 \pm 1.38$ hours and $6.49 \pm 1.70$ hours respectively. All the women delivered within 12 hours of active labour. Difference was not statistically significant. Mean ROM to delivery interval in group A and B was $16.31 \pm 8.67$ hours and $13.85 \pm 5.46$ hours respectively. Duration is more in expectant management; the difference is statistically significant ( $\mathrm{p}$ value by independent $\mathrm{t}$ test $=0.025$ ).

Most of the women in both the groups delivered within 12 to 24 hours interval. As explained, duration of ROM to delivery interval was more in expectant management group; 17 women in this group had ROM to delivery interval more than 24 hours. This proves definite risk of increased duration of ROM to delivery interval in expectant management group ( $\mathrm{p}$ value by Chi square test=0.002). Induction to delivery interval in immediate induction group was $11.48 \pm 6.15$ hours. In expectant management group 11 women required induction of labour at 24 hours interval from ROM who did not go into spontaneous labour. Out of 11 in only 2 women induction to delivery interval was beyond 12 hours. The details are shown in Table 6. Among other maternal factors; hospital stay was $5.40 \pm 0.81$ days and $4.11 \pm 0.86$ days in group A and $\mathrm{B}$ respectively. The duration is more in expectant management group.

As operative interventions increase the duration of hospital stay, the duration of hospital stay was on higher side in immediate induction group too. The difference was not statistically significant. Infective morbidity i.e., clinical chorioamnitis, puerperal pyrexia were less in both groups. These are more in expectant group, but differences are not statistically significant. Fetal distress was noted in $9 \%$ and $15 \%$ of patients in group A and B respectively. The observation more found in immediate induction group. Among others, the incidence of PPH was less. Active management of third stage of labour was followed for all the patients. No statistically significant difference noted. Neonatal factors in both the groups compared are depicted (Table 7); the differences were not statistically significant.

Table 1: Maternal age (years), gestational age (weeks) and parity.

\begin{tabular}{|llll|}
\hline Variables & Group & & \\
Expectant management (A) & \multicolumn{2}{c|}{ Immediate induction (B) } & P value \\
\hline Age (years) & $25.72 \pm 3.59$ & $25.48 \pm 3.40$ & 0.628 \\
\hline Gestational age (weeks) & $38.08 \pm 0.98$ & $38.30 \pm 0.82$ & 0.088 \\
\hline
\end{tabular}




\begin{tabular}{|c|c|c|c|}
\hline \multirow{2}{*}{ Variables } & \multicolumn{2}{|l|}{ Group } & \multirow{2}{*}{ P value } \\
\hline & Expectant management (A) & Immediate induction (B) & \\
\hline \multicolumn{4}{|l|}{ Parity } \\
\hline 0 & $73(73 \%)$ & $75(75 \%)$ & \\
\hline $1,2,3$ & $27(27 \%)$ & $25(25 \%)$ & 0.747 \\
\hline
\end{tabular}

Table 2: Mode of delivery.

\begin{tabular}{|llll|}
\hline Mode of delivery & Group A (\%) & Group B (\%) & P value \\
\hline LSCS & $23(23)$ & $37(37)$ & 0.096 \\
\hline Operative vaginal delivery & $9(9)$ & $7(7)$ & $56(56)$ \\
\hline Spontaneous vaginal delivery & $68(68)$ & 5 \\
\hline
\end{tabular}

Table 3: Mode of delivery comparing caesarean section versus vaginal birth.

\begin{tabular}{|llll|}
\hline Mode of delivery & Group A (\%) & Group B (\%) & P value \\
\hline LSCS & $23(23)$ & $37(37)$ & 0.031 \\
\hline Vaginal delivery & $77(77)$ & $63(63)$ & \\
\hline
\end{tabular}

Table 4: Parity wise mode of delivery.

\begin{tabular}{|lll|}
\hline $\begin{array}{l}\text { Mode of delivery } \\
\text { Nullipara }\end{array}$ & Group A (\%) & Group B (\%) \\
\hline LSCS & $20(27.40)$ & $32(42.67)$ \\
\hline Vaginal delivery & $53(72.60)$ & $43(57.33)$ \\
\hline Multipara & & \\
\hline LSCS & $03(11.11)$ & $05(20.00)$ \\
\hline Vaginal delivery & $24(88.89)$ & $20(80.00)$ \\
\hline
\end{tabular}

Table 5: Number of vaginal examinations.

\begin{tabular}{|c|c|c|c|}
\hline No. of vaginal examinations & Group A (\%) & Group B (\%) & $P$ value \\
\hline$\leq 4$ & $70(70)$ & $81(81)$ & \multirow{3}{*}{0.048} \\
\hline $5-8$ & $26(26)$ & $19(19)$ & \\
\hline$\geq 9$ & $4(4)$ & $0(0)$ & \\
\hline
\end{tabular}

Table 6: Rupture of membranes (ROM) to delivery interval and induction to delivery interval.

\begin{tabular}{|llll|}
\hline Variables & Group A (\%) & Group B (\%) & P value \\
\hline ROM to delivery interval (hours) & $16.31 \pm 8.67$ & $13.85 \pm 5.46$ & 0.0256 \\
\hline$<12$ & $36(36)$ & $29(29)$ & 0.0021 \\
\hline $12-24$ & $47(47)$ & $67(67)$ & $4(4)$ \\
\hline$>24$ & $17(17)$ & $11.48 \pm 6.15$ & - \\
\hline Induction to delivery interval (hours) & NA & $54(54)$ & - \\
\hline$<12$ & - & $43(43)$ & - \\
\hline $12-24$ & - & $3(3)$ & - \\
\hline$>24$ & - & & \\
\hline
\end{tabular}

Table 7: Neonatal outcomes.

\begin{tabular}{|llll|}
\hline Neonatal outcome & Group A (\%) & Group B (\%) & P value \\
\hline Apgar score $\leq 7$ at 5 min & $7(7)$ & $10(10)$ & 0.998 \\
\hline Resuscitation with PPV & $4(4)$ & $6(6)$ & 1.06 \\
\hline NICU admission & $7(7)$ & $5(5)$ & 0.767 \\
\hline Ventilatory support & $1(1)$ & $2(2)$ & 1.00 \\
\hline Neonatal sepsis & $4(4)$ & $2(2)$ & 0.683 \\
\hline
\end{tabular}




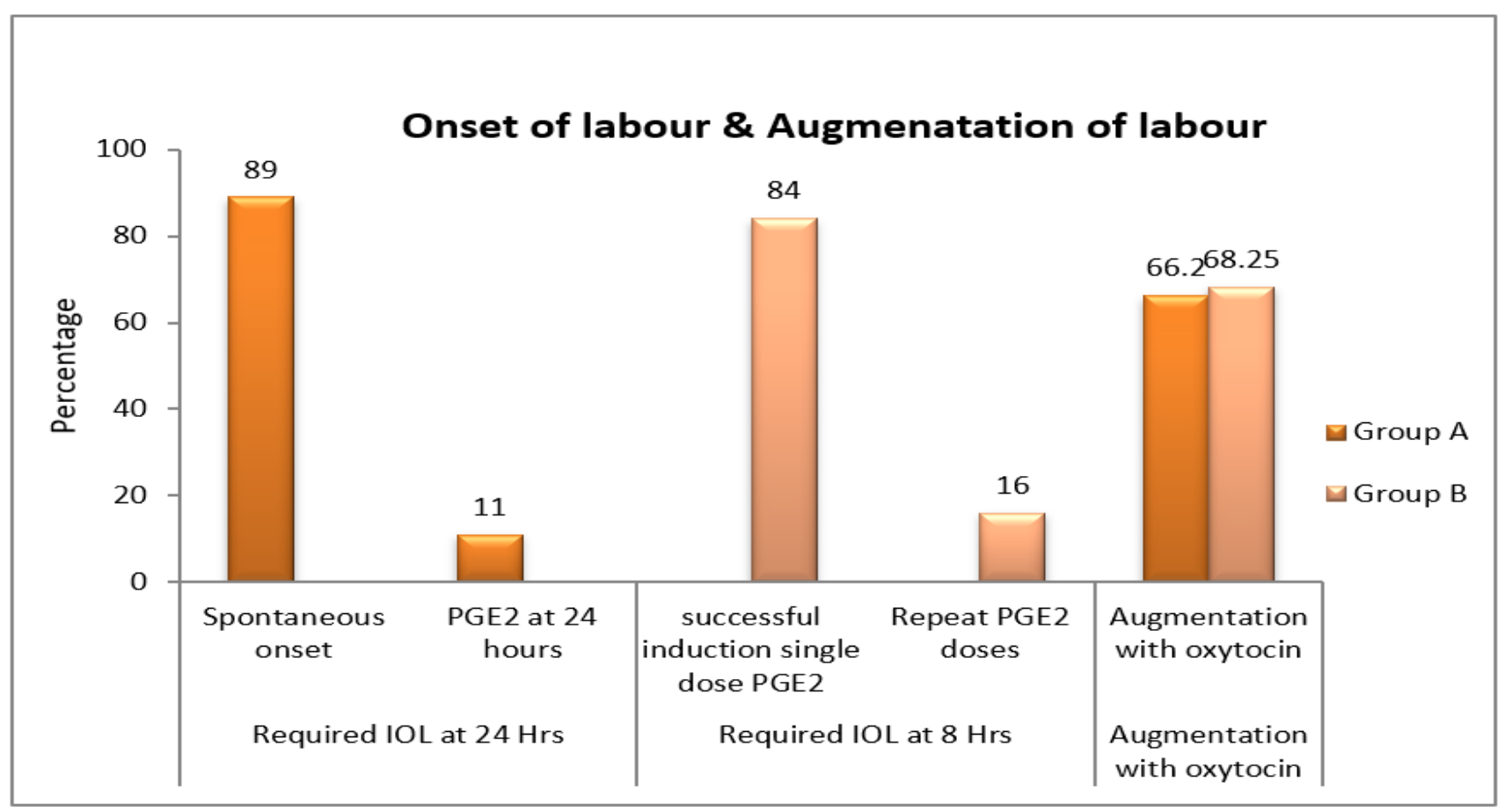

Figure 1: Onset of labour and requirement of oxytocin for augmentation of labour.

\section{DISCUSSION}

Though PROM is not uncommon, the management even at term is controversial and there is no consensus for definite protocol of management. Earlier reports favoured induction based upon findings that the risks of maternal or neonatal infection are increased with longer durations of ruptured membrane. But recent studies have shown that expectant management was safe and more successful in achieving vaginal delivery.

The baseline demographic characteristics were same as compared to the studies reviewed. In the comparative study by Chaudari et al $75.33 \%$ of women included were nullipara. ${ }^{5}$ In the present study too most of the women (about 68\%) were primigravida. Total nullipara were $74 \%$. It reflects that incidence is high in primigravida. In the present study $89 \%$ women in expectant group went into spontaneous labour within $24 \mathrm{hrs}$. In a study conducted by Shah et al $77.5 \%$ women in expectant group went into labour spontaneously within 24 hours. $^{6}$ In a study conducted by Shalev et al total $45 \%$ women went into spontaneous labour within 12 hours and total $85 \%$ over a period of 3 days. ${ }^{7}$ While in a study by George SS et al $35.6 \%$ of primigravida women and $55.5 \%$ of multigravida went into spontaneous labour within 12 hours. ${ }^{8}$ Gonen et al reported that $93 \%$ women in immediate induction group went into labour after single application of $\mathrm{PGE}_{2}$ gel. ${ }^{9}$ And in the studies by Chaudari et al and Shah et al 91.89 and $81 \%$ women went into labour respectively after single application of gel. This is comparable to the present study where $84 \%$ went into labour after single application of $\mathrm{PGE}_{2}$ gel.

In a study conducted by Meikle et al $64 \%$ women required augmentation of labour by oxytocin in immediate induction group. ${ }^{10}$ In the studies by Chaudari et al and Poornima et al, respectively $32.43 \%$ and $56 \%$ women in Induction group required augmentation by oxytocin; whereas respectively $82.14 \%$ and $65 \%$ women in expectant group required augmentation. ${ }^{5,11}$ This comparison was statistically significant $(\mathrm{p}<0.01)$, but in both these studies criteria for expectant management was different from the present study, which was expectancy of 12 hours followed by immediate induction of labour by oxytocin. In the present study $66.20 \%$ women in expectant group (51/77) and $68.25 \%$ women in induction group (43/63) required augmentation of labour by oxytocin; statistically not significant. The rate of caesarean section in immediate induction group by Gibbs et al was 39\%, $17.8 \%$ by Snehamay et al $22 \%$ by Krupa Shah et al and $37 \%$ in the present study. ${ }^{5,6,12}$ In the expectant group the rate of CS was $28.5 \%$ in Chaudari et al group, $24 \%$ by Shah et al and $23 \%$ in the present study. ${ }^{5,6}$ Recent study by Gupta et al in 2018 concluded that caesarean section rates and fetal distress are significantly less compared to active management group. ${ }^{15}$ In present study LSCS rate is more in immediate induction group compared to expectant group (37\% vs $23 \%$ ) giving us rate of vaginal deliveries as $63 \%$ vs $73 \%$ respectively, which is statistically significant $(\mathrm{p}<0.05)$. 
The operative vaginal delivery rate was $17 \%$ in expectant management group in a study by Conway et al and it was $19.1 \%$ in immediate induction group in a study by Chua et al, Arulkumaran et al. ${ }^{13,14}$ By Chaudhuri et al group operative vaginal delivery rate was significantly higher in expectant management group $14.2 \%$ as compared to immediate induction group of $3.5 \% .^{5}$ In the present study operative vaginal deliveries were $9 \%$ and $7 \%$ in expectant and immediate induction group respectively. The variation in the results may be attributed to the different format of expectant group in the various studies and institute-based variations in management of labour. Recent studies by Rawat et al in 2018 and Savitha et al in 2017 concluded that there were no statistically significant differences in the rate of maternal and neonatal morbidity among major outcomes compared above among both the groups. ${ }^{16,17}$ Savitha et al had used tab. Misoprostol in immediate induction group and had high rate of vaginal deliveries. ${ }^{17}$ The results concur findings in the present study.

Limitations of the present study can be enumerated asnumber of women included in the study were less, duration of study was only two years, randomization can become difficult considering obstetrician's choice of mode of management, number of vaginal examinations are high in expectant management group, increased hospital stay and high cost factor in expectant management group.

Table 8: Caesarean section rate compared in different studies.

\begin{tabular}{|lll|}
\hline Authors & Expectant management group (\%) & Immediate induction group (\%) \\
\hline Gibbs et al (1982) & - & 39 \\
\hline Chaudari et al (2006) & 28.5 & 17.8 \\
\hline Shah et al (2012) & 24 & 22 \\
\hline Gupta et al (2018) & 2 & 16 \\
\hline Present study & 23 & 37 \\
\hline
\end{tabular}

Table 9: Maternal outcome in comparative studies.

\begin{tabular}{|c|c|c|c|c|c|c|}
\hline \multirow{2}{*}{$\begin{array}{l}\text { Maternal } \\
\text { outcome }\end{array}$} & \multirow{2}{*}{$\begin{array}{l}\text { George et al } \\
(2003)^{8} \\
\text { A }\end{array}$} & \multirow{2}{*}{$\begin{array}{l}\text { Chou et al, } \\
\text { Arulkumar et al (1991) } \\
\text { B }\end{array}$} & \multicolumn{2}{|c|}{ Chaudari et al $(2006)^{5}$} & \multicolumn{2}{|c|}{ Present study } \\
\hline & & & $\mathbf{A}$ & B & $\mathbf{A}$ & B \\
\hline $\begin{array}{l}\text { ROM to } \\
\text { delivery interval }\end{array}$ & $21.13 \pm 7.2$ & 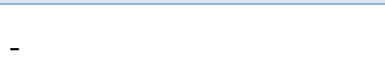 & $21 \pm 10.3$ & $17 \pm 10.3$ & $16.31 \pm 8.67$ & $13.85 \pm 5.46$ \\
\hline $\begin{array}{l}\text { Duration of } \\
\text { active labour }\end{array}$ & $3.7 \pm 5$ & $8.6 \pm 3.9$ & $3.79 \pm 2$ & $3.89 \pm 2.6$ & $7.31 \pm 1.38$ & $6.49 \pm 1.70$ \\
\hline $\begin{array}{l}\text { No. of vaginal } \\
\text { examination }>4 \\
(\%)\end{array}$ & 43 & - & 46 & 40 & 26 & 19 \\
\hline
\end{tabular}

\section{CONCLUSION}

An expectant management allows a good number of women to go into labour without an increase in caesarean section rate and infectious morbidity for mother and fetus. Hence in Term PROM Expectant management with 24 hours of waiting is desirable, it gives good chance of spontaneous onset of labour in women and would help reducing caesarean section rate without increasing risk of infective morbidity. Prophylactic antibiotics must be administered to mother and neonate. Number of vaginal examinations must be restricted. Patients must be counselled adequately to relieve their anxiety about long period of expectancy and waiting.

\section{ACKNOWLEDGMENTS}

Authors would like to thank Dr. Shankar Prasad, Medical Director of the institute, all clinical and para clinical staff members who helped in this prospective study.
Funding: No funding sources

Conflict of interest: None declared

Ethical approval: The study was approved by the Institutional Ethics Committee

\section{REFERENCES}

1. Condous G, Timmerman D, Goldstein S, Valentin L, Jurkovic D, Bourne T. Pregnancies of unknown location: consensus statement. Ultrasound Obstet Gynecol. 2006;28(2):121-2.

2. Duff P. Premature rupture of the membranes in term patients: induction of labor versus expectant management. Clin Obstet Gynecol. 1998;41(4):88391.

3. Ozden S, Delikara MN, Avci A, Fiçicioglu C. Intravaginal misoprostol vs. expectant management in premature rupture of membranes with low Bishop scores at term. Int J Gynaecol Obstet. 2002;77(2):10915.

4. Hoffmann RA, Anthony J, Fawcus S. Oral misoprostol vs. placebo in the management of 
prelabor rupture of membranes at term. Int J Gynaecol Obstet. 2001;72(3):215-21.

5. Chaudari Snehamay. PROM at term - immediate induction with PGE 2 gel compared with delayed induction with oxytocin. J Obstet Gynecol Ind. 2006;56(3):224-9.

6. Shah K, Doshi H. Premature rupture of membrane at term: early induction versus expectant management. J Obstet Gynaecol India. 2012;62(2):172-5.

7. Shalev E, Peleg D, Eliyahu S, Nahum Z. Comparison of 12- and 72-hour expectant management of premature rupture of membranes in term pregnancies. Obstet Gynecol. 1995;85(5):766-8.

8. George SS, Gangarani VS, Shesadri L. Term PROMA $12 \mathrm{hr}$ expectant management. J Obstet Gynecol India. 2003;53:230-3.

9. Gonen R, Samberg I, Degani S. Intracervical prostaglandin E2 for induction of labor in patients with premature rupture of membranes and an unripe cervix. Am J Perinatol. 1994;11(6):436-8.

10. Meikle SF, Bissell ME, Freedman WL, Gibbs RS. A retrospective review of the efficacy and safety of prostaglandin E2 with premature rupture of the membranes at term. Obstet Gynecol. 1992;80(1):769.

11. Poornima B, Dharma RDB. Premature Rupture of Membranes at Term: Immediate Induction With PGE(2) Gel Compared With Delayed Induction With Oxytocin. J Obstet Gynaecol India. 2011;61(5):516-8.

12. Gibbs RS, Blanco JD. Premature rupture of the membranes. Obstet Gynecol. 1982;60(6):671-9.
13. Conway DI, Prendiville WJ, Morris A, Speller DC, Stirrat GM. Management of spontaneous rupture of the membranes in the absence of labor in primigravid women at term. Am J Obstet Gynecol. 1984;150(8):947-51.

14. Chua S, Arulkumaran S, Kurup A, Anandakumar C, Tay D, Ratnam SS. Does prostaglandin confer significant advantage over oxytocin infusion for nulliparas with pre-labor rupture of membranes at term? Obstet Gynecol. 1991;77(5):664-7.

15. Gupta A, Gautam S, Prakash O, Chauhan M. Early induction versus expectant management in prelabour rupture of membranes. Int J Reprod Contracept Obstet Gynecol. 2018;7:4634-9.

16. Rawat R, Divedi P, Debbarma S, Vishwakarma S, Mittal N. A comparative study between active and expectant management of premature rupture of membranes at term on fetomaternal and perinatal outcome in rural population. Int J Reprod Contracept Obstet Gynecol. 2018;7:2393-8.

17. Savitha TS, Pruthvi S, Sudha CP, Nadig VS. A comparative study of feto-maternal outcome in expectant management versus active management in pre-labor rupture of membranes at term. Int J Reprod Contracept Obstet Gynecol. 2018;7:146-51.

Cite this article as: Tambvekar SE, Gudi SN. Obstetric and perinatal outcomes of expectant management and immediate induction of labour in term premature rupture of membranes: promising outcomes from expectant management cohort. Int $\mathbf{J}$ Reprod Contracept Obstet Gynecol 2022;11:378-84. 